Please do not remove this page

RMIT

UNIVERSITY

\title{
The ethics of offsetting nature
}

Ives, Christopher; Bekessy, Sarah

https://researchrepository.rmit.edu.au/esploro/outputs/9921862614501341/filesAndLinks?institution=61RMIT_INST\&index=null

Ives, C., \& Bekessy, S. (2015). The ethics of offsetting nature. Frontiers in Ecology and the Environment, 13(10), 568-573. https://doi.org/10.1890/150021

Document Version: Accepted Manuscript

Published Version: https://doi.org/10.1890/150021

Repository homepage: https://researchrepository.rmit.edu.au

(c) The Ecological Society of America

Downloaded On 2023/04/27 00:11:17 +1000

Please do not remove this page 
Thank you for downloading this document from the RMIT Research Repository.

The RMIT Research Repository is an open access database showcasing the research outputs of RMIT University researchers.

RMIT Research Repository: http://researchbank.rmit.edu.au/

\section{Citation: \\ Ives, C and Bekessy, S 2015, 'The ethics of offsetting nature', Frontiers in Ecology and the Environment, vol. 13, no. 10, pp. 568-573.}

See this record in the RMIT Research Repository at:

https://researchbank.rmit.edu.au/view/rmit:35521

Version: Published Version

Copyright Statement:

(C) The Ecological Society of America

Link to Published Version:

http://dx.doi.org/10.1890/150021 


\title{
The ethics of offsetting nature
}

\author{
Christopher D Ives ${ }^{\dagger *}$ and Sarah A Bekessy
}

\begin{abstract}
Biodiversity offsetting is transforming conservation practice around the world. Development activities that degrade or destroy biodiversity at one location are now increasingly acceptable because of compensatory environmental gains generated elsewhere. This change represents a major shift in how nature is protected, and yet its philosophical justification has received little attention. We argue that biodiversity offsetting aligns most easily with a utilitarian ethic, where outcomes rather than actions are the focus. However, offsetting schemes often neglect to account for the multiple values that people assign to biodiversity - including unique, place-based values. Furthermore, the implications of defining nature as a tradeable commodity may affect our sense of obligation to protect biodiversity. Ironically, offsetting may exacerbate environmental harm because it erodes ethical barriers based on moral objections to the destruction of biodiversity. By failing to consider the ethical implications of biodiversity offsetting, we risk compromising the underlying motivations for protecting nature.
\end{abstract}

Front Ecol Environ 2015; 13(10): 568-573, doi:10.1890/150021

$\mathrm{T}$ he use of offsets to mitigate biodiversity losses has proliferated in recent years. Most of the approximately 51 schemes operating around the world have emerged over the past 10 years (Figure 1). Increasingly, more traditional systems for safeguarding biodiversity are being discarded in favor of options that "trade nature".

Offsetting policies seek to compensate for biodiversity losses at an impact site by generating ecological gains elsewhere (Maron et al. 2012). This increased flexibility is intended to facilitate both economic development and environmental protection, and is an appealing option to developers and policy makers. Yet there is fierce debate concerning the validity of offsetting (Vidal 2014), with opinions divided among various stakeholders. For instance, in a recent online public consultation undertaken by the European Commission, there was an almost 50/50 split between survey respondents who thought bio-

\section{In a nutshell:}

- Biodiversity offsetting schemes (those that enable biodiversity losses to be compensated by gains elsewhere) have increased in number globally

- Many questions about the ethics of this approach to conservation are missing from the literature, yet these issues are at the heart of public debate

- Biodiversity offsetting resonates most strongly with an "outcomes-based" form of nature conservation, rather than one focused on regulating actions

- Current schemes do not adequately account for the multiple values that people assign to biodiversity

- Offsetting may decrease society's sense of obligation to protect biodiversity by framing biodiversity destruction as a technical, economic problem rather than a moral and ethical one

School of Global, Urban and Social Studies, RMIT University, Melbourne, Australia; current address: Faculty of Sustainability, Leuphana University, Lüneburg, Germany*(chris.ives@leuphana.de) diversity offsetting was appropriate and those who thought otherwise (European Commission 2015).

Opinions are similarly divided in the scholarly literature, with some heralding the potential positive gains for biodiversity from offsetting (Bayon and Jenkins 2010) and others expressing doubts (Walker et al. 2009). One area of concern is that offsetting results in poorer environmental outcomes for legal or political reasons. While biodiversity offsetting is intended as a "last resort", to be applied exclusively to residual impacts of a development project after efforts have been made to avoid and minimize environmental harm (BBOP 2012), political and economic motivations regularly outweigh or undermine environmental protection (Gibbons and Lindenmayer 2007; Walker et al. 2009; Gordon et al. 2015). From a scientific perspective, additional concerns include the (in)ability of biodiversity offsets to achieve genuine compositional and functional equivalence (Maron et al. 2012).

Some concerns, however, transcend scientific or technical reasoning. They are ethical in nature and lie at the heart of the current debate. Many conservation scientists and environmentalists disagree fundamentally with market-based conservation schemes such as biodiversity offsetting, believing that such approaches are incongruous with nature's intrinsic value (McCauley 2006). Yet these ethical concerns have often been conflated with comments about the technical design of these schemes. For instance, jurisdictions differ in their approaches to "inkind" offsets (ie requiring trades to be of identical type and location) versus "out-of-kind" offsets (ie permitting trades between different kinds of ecological entities; Bull et al. 2013). These dimensions cannot be resolved on ecological grounds alone but relate to the underlying reasons why we want to conserve biodiversity. The same is true for the mitigation hierarchy - the sequential procedure of first avoiding and minimizing biodiversity impacts and rehabilitating damaged ecosystems, before offsetting the 


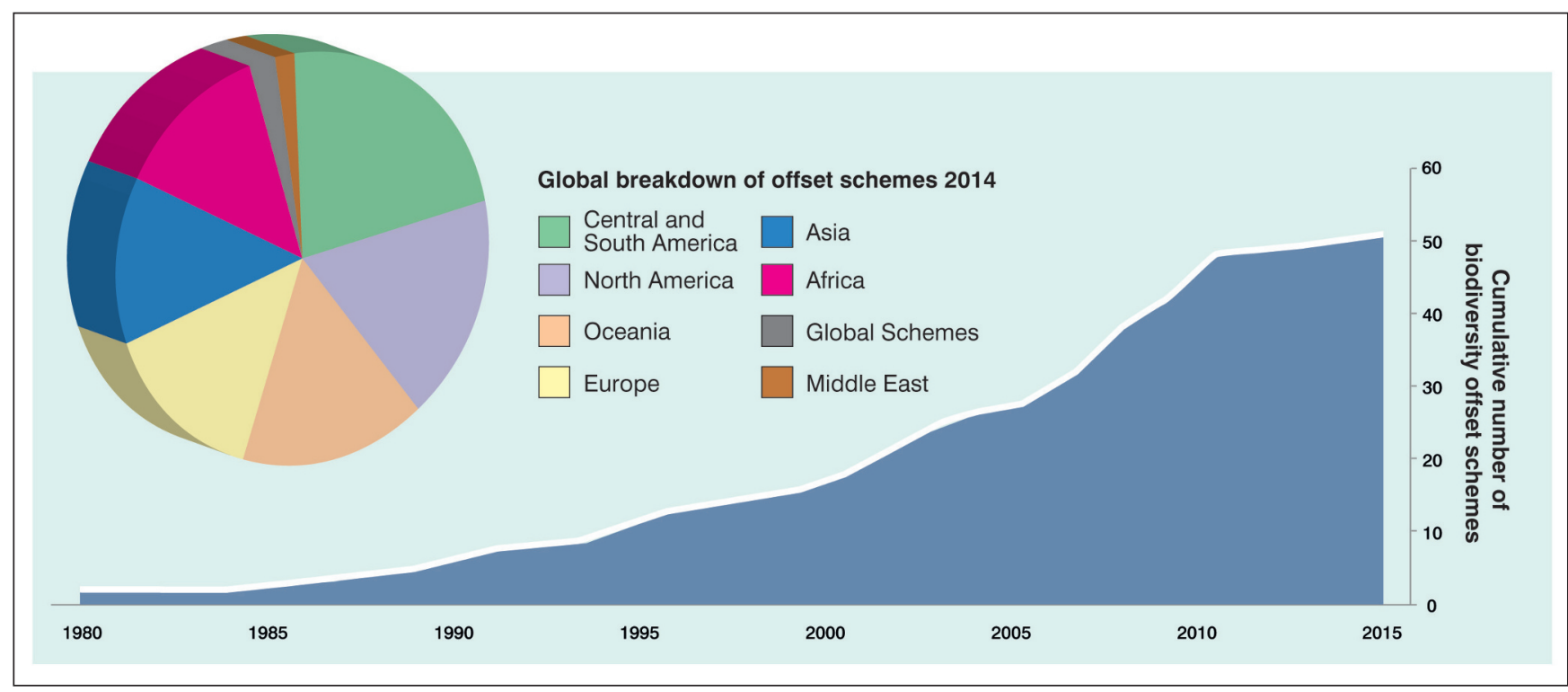

Figure 1. Increase in offset schemes around the world. The pie chart presents a breakdown of these data by region. Of the approximately 51 operational schemes (including compulsory and voluntary schemes and those under trial), most have emerged over the past 10 years. Data were collated via a review of academic and gray literature and consultation with academic experts on biodiversity offsetting.

biodiversity impacts that remain (BBOP 2012). Without exploring the ethical implications of biodiversity offsetting, scientists and policy makers risk evaluating its technical feasibility rather than its justification according to the reasons for conservation practice (Sagoff 2013).

Ethical questions that underpin the debate about biodiversity offsetting are largely absent in both the academic literature and public discourse (but see Spash [in press]). For example, if it is acceptable to offset residual impacts of a development project, why make any attempt to first avoid or minimize unnecessary impacts if these too can be offset without reducing net ecological outcomes? Can the protection of organisms in one place compensate for the willful destruction of others at another location? Is it necessary (or possible) to offset the reduction in human wellbeing associated with biodiversity loss? If nature is treated as a tradeable commodity, does this remove an ethical barrier to its destruction? What does the buying and selling of biodiversity credits say about our relationship to the natural world? Here we argue that the legitimacy of biodiversity offsetting must be evaluated according to various ethical theories.

\section{Offsetting reflects a shift in conservation's ethical foundations}

The imperative to conserve biodiversity can be derived from multiple ethical bases, yet these are rarely made explicit within legislation. Thus, the moral legitimacy of a new legal mechanism for conservation needs to be scrutinized according to different schools of ethical thought.

Ethics can be broadly represented by three different approaches: (1) consequentialist ethics (of which utilitarianism is the dominant form and will be considered here), which focuses on the expected outcomes of actions; (2) deontological (or Kantian) ethics, which focuses on the actions themselves (with actions usually evaluated according to a rule or rules); and (3) virtue ethics, which emphasizes the virtues or moral character behind actions. There is great debate among ethicists concerning which approach is most robust and useful in different moral contexts (Shafer-Landau 2013). With the rise of environmentalism, ethicists have looked to apply such traditional approaches to new environmental problems. This has proven challenging because these approaches were developed to help guide actions that are made by and that influence humans. For these ethical approaches to inform behavior toward the environment, either an improved recognition of the connections between people and nature is required, or an expansion of moral responsibilities of humans toward the non-human realm is needed (Sarkar 2012).

Traditional biodiversity legislation has prohibited certain actions (eg clearing high-quality remnant vegetation or harming endangered species) according to clearly defined statutes (eg the "taking" of endangered species under the US Endangered Species Act; Ruhl 1999). Although derived from different ethical theories, the justification for law and policy might find the strongest support from a deontological framework. Deontological ethics can be either agent-centered (focused on the person undertaking an action) or patient-centered (focused on the one being acted upon). Thus, when applied to the environment, justification for environmental laws comes from the moral concept that either people should not harm biodiversity (agent-centered theory) or the integrity of the environment should be upheld (patient-centered theory). Accordingly, the act of destroying biodiversity would have 
(and indeed has) been considered wrong and to be avoided where possible, even under challenging circumstances. In this way, biodiversity legislation is analogous to laws governing actions toward human beings. For instance, the crime of assault represents a breaking of the law, irrespective of any good the perpetrator may have performed beforehand or that results afterwards.

Given that biodiversity offsetting emphasizes outcomes rather than the activities that harm biodiversity, this approach differs from traditional legislation that focuses on regulating the actions that cause environmental impacts. With biodiversity offsetting, there is no clear rule to break; one just has to find an appropriate biodiversity gain that can be traded in compensation for ecological losses. This appears to appeal to a utilitarian ethical justification, but this is not necessarily a problem. Utilitarian ethics is well-established and has been the dominant ethical system in the development of Western liberal democracy and values. Classic utilitarianism assesses an action based on the expected good that will result. This requires clear articulation of what constitutes "good" (eg desire satisfaction or preference fulfillment) and how it can be valued. This is a key challenge in philosophy but is particularly difficult in the context of applying utilitarian ethics to biodiversity offsetting for two reasons. First, scientifically defensible measurements of biodiversity are needed to determine a unit of trade, and second, a robust method of determining the value of a biodiversity unit is required.

\section{Measuring biodiversity}

Determining a consistent, interchangeable unit of trade is especially challenging for biodiversity because it is a complex, dynamic entity composed of multiple concepts such as species richness and rarity, ecological complementarity and function, and genetic diversity (Purvis and Hector 2000; Bull et al. 2013). Some biodiversity offsetting schemes focus on gains and losses in relation to a single aspect of biodiversity (eg threatened species populations or habitats), yet this approach can fail to adequately conserve the broader ecosystem elements associated with a species or population. In many other cases, metrics of trade are based on a biodiversity "score" (eg "habitat hectares"; Parkes et al. 2003), which is used to trade biodiversity "units" to achieve a predefined objective (eg net gain or no net loss). This method of ecological accounting is of practical convenience since it allows patches of habitat to be traded, irrespective of ecological differences. However, by conflating the many attributes of biodiversity, this practice ignores the fact that "biodiversity cannot be reduced sensibly to a single number" (Purvis and Hector 2000). Some schemes have addressed this issue by prohibiting trading between different ecosystem types (out-of-kind compensation), yet ecological equivalence is difficult to achieve even with this restriction in place (Bull et al. 2013). Ultimately, defining a unit of trade is so challenging because it is not an ecological question. Rather, it is connected to the underlying motivations for protecting biodiversity, which are often difficult to articulate (Miller et al. 2011).

The very presence of the mitigation hierarchy highlights a lack of confidence in the ability of current assessment methods to measure biodiversity adequately and capture its importance. Proponents of biodiversity offsetting argue that it should only be applied to residual or "unavoidable" impacts from a development project. Yet to date, there has been no clear ethical explanation for why offsetting should function only as a "last resort" within the mitigation hierarchy. If (1) scientific measurements of biodiversity are equated with their importance, (2) biodiversity is measured accurately, and (3) measured losses are adequately compensated for, then the requirement to first avoid and minimize impacts or restore biodiversity onsite might appear unnecessary. The absence of a transparent, logical basis for the mitigation hierarchy is leading to a slackening of the requirements, particularly when the economic costs of avoiding or minimizing impacts to biodiversity far outweigh those related to offsetting. Permitting offsetting without reference to ethical reasons why it should be used to compensate for unavoidable impacts alone is resulting in offset gains being used to justify impacts that previously would not have been acceptable.

Uneasiness about the ability of existing metrics to measure the importance of biodiversity appropriately is also revealed through legal stipulations about what types of impacts (or ecological entities) can or cannot be offset. Many jurisdictions prevent offsetting of impacts to threatened species or habitats. In this way, these offset policies are something of a hybrid of utilitarian ethics (they permit biodiversity impacts yet maintain environmental "values" through compensation) and deontological ethics (certain types of biodiversity are off-limits). Again, a lack of philosophical clarity has led to a gradual shift between these two stances over time as restrictions are removed. In Australia, a leading jurisdiction in the implementation of offsets, the practice of trading biodiversity was initially highly conservative. Offsetting was applicable only for impacts on common vegetation types, requiring improvements in equivalent communities (like-forlike offsetting) (Victorian Government 2002). After increasing pressure from industry, out-of-kind offsets (ie gains in a different community type) were permitted, along with offsetting of listed threatened species, even those that are critically endangered. Today, biodiversity offset credits in some parts of Australia can be purchased "over the counter" and can comprise entirely disparate entities. For example, the impacts of a port development on endangered dugongs (Dugong dugon) have been offset (in part) by signage to encourage recreational boat users to decrease their speed to reduce the likelihood or severity of boat strikes (Figure 2; Gladstone Ports Corporation 2012). 

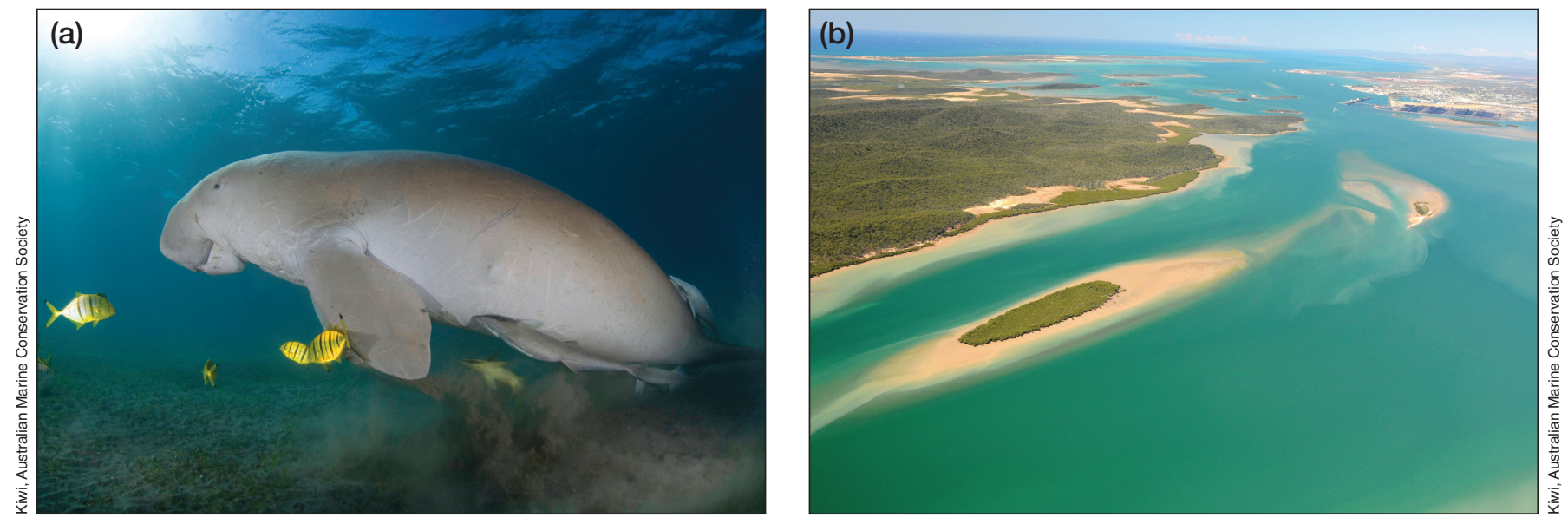

Figure 2. Impacts to dugongs (a) from a port development in Gladstone Harbour, Australia, have been offset using out-ofkind gains. The scale of the impacts to the system is clear when comparing photographs from before (b) and after (c) the development.

\section{Scientific equivalence is not value equivalence}

Even if it were possible to determine a consistent unit to evaluate ecological equivalence between biodiversity impacts and biodiversity offsets, this still would not be a sufficient utilitarian ethical justification of biodiversity offsetting. According to utilitarian ethics, for an outcome to be morally valid, it is not the scientific equivalence that matters, but value equivalence. This would require consideration of which values are relevant, and whose values should be taken into account.

People assign a range of use and non-use values to nature, including subsistence, economic, aesthetic, therapeutic, and bequest value (UNEP 2005). Thus, many people may object to offset agreements not only because different biodiversity features are incomparable scientifically but also because the offsets and losses are not perceived to have the same value. Moreover, the values of ecosystems that commonly matter most to people - such as aesthetic beauty, cultural importance, opportunities for social interaction, or existence value (simply knowing it is there) - are intangible and difficult to quantify (Kenter et al. 2015). These values are rarely, if ever, accounted for in biodiversity offsetting and may require qualitative rather than quantitative techniques for adequate assessment. Of course, if one considers nature to possess intrinsic value (that is, its value is independent of a valuer; see Vucetich et al. 2015), then biodiversity offsetting may be impractical because intrinsic values cannot be measured, prioritized, or traded off (Justus et al. 2009). In some ways, the challenge of capturing the values of biodiversity is an expression of the cost-benefit analysis quandary in environmental management, whereby the aggregation of individual stated preferences according to utilitarian economic theory does not result in ultimately desirable and just public outcomes (see, for example, Sagoff 2008).

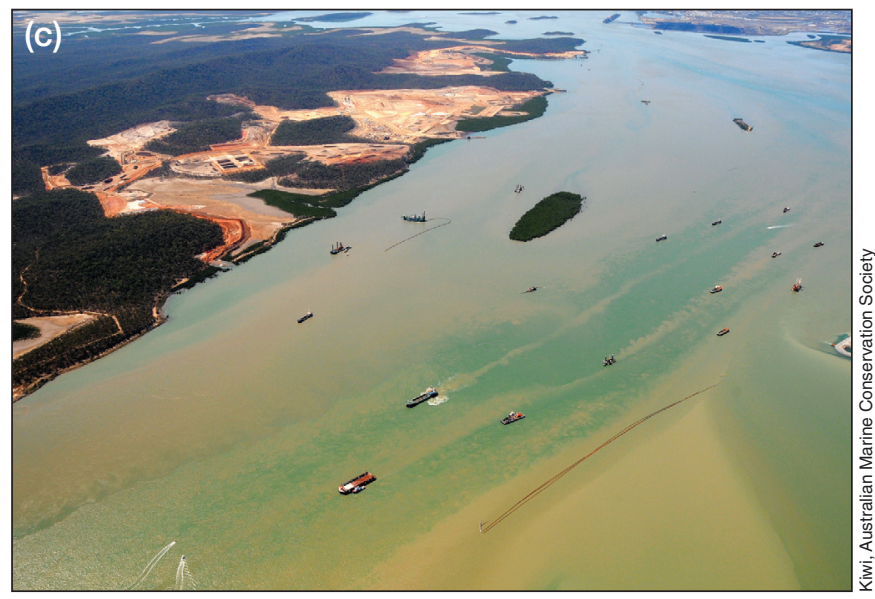

Biodiversity offsetting has been compared to carbon offsetting - an approach that, while contentious, is considered by many scholars to be the most efficient way of curbing atmospheric carbon emissions. However, biodiversity is quite unlike carbon. Trading metric tons of carbon is simple ethically because carbon molecules generally do not matter to people. The value that is assigned to carbon is representative of its influence on other things that are valued, such as human life, ecological outcomes, and economic systems. Applying a market mechanism to biodiversity is much more ethically complex because biodiversity itself is valued by people and because values associated with biodiversity typically pertain to specific species, habitats, and ecosystems.

Another key consideration, according to utilitarian ethics, is whose values are considered in a decision. Using ecological features alone to calculate numerical scores for habitat patches assumes that biodiversity is valued equally everywhere by everyone. Of course, this assumption is inappropriate, given that different people will assign greater or lesser value to biodiversity for many reasons beyond its ecological condition or composition. Indeed, people's attachment to specific places is often very strong (Low and Altman 1992) and is related to unique meanings that certainly cannot be traded between different locations. Consider the offsetting of biodiversity losses on the fringes of urban settlements arising from 


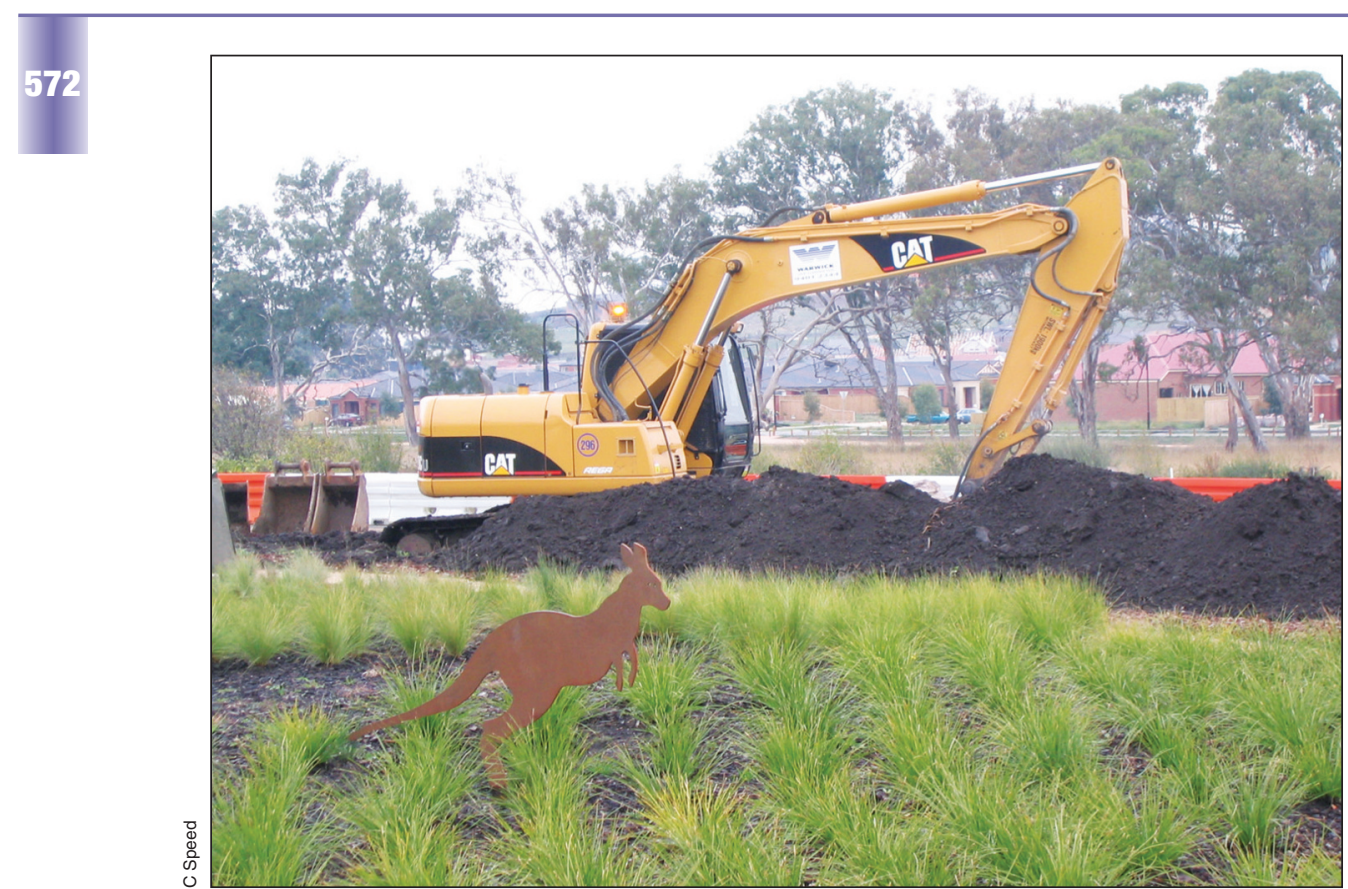

Figure 3. A residential development site in northern Melbourne, Australia, whereby impacts to the grassland ecosystem were offset elsewhere. Installations of metal wildlifethemed statues as part of an interpretive walk only serve to highlight the loss of biodiversity from the area.

new housing developments (Bekessy et al. 2010). Creating offset sites away from where the biodiversity is being destroyed means that nature-based recreation and environmental education opportunities are lost, natural amenities and environmental health are reduced, and places that shaped unique memories are markedly transformed (Figure 3). It is therefore unlikely that the offset sites will be valued in the same way or to the same degree as the original biodiversity located close to where people live. Furthermore, while the economic and social gains resulting from development projects may appear very large, they are typically concentrated to a small number of people. In contrast, the instrumental values of natural ecosystems are typically diffuse yet benefit many (Rolston 1988).

Is it possible to adequately account for the range of values that are associated with biodiversity in order for offsetting to be ethically viable? While recent progress has been made in ecosystem services research along these lines (Daniel et al. 2012; Jax et al. 2013), assessing the diversity of values that people relate to biodiversity remains a daunting task and currently no biodiversity offsetting scheme comes close to doing so.

\section{Offsetting may undermine environmental virtues}

Allowing for the buying and selling of nature may counteract the development of respectful, positive societal attitudes toward nature: the motivation for conservation according to a virtue ethics framework. Hursthouse (2007) noted that environmentalists routinely identify traditional vices, such as greed and self-indulgence, as underpinning environmental problems. She argued for a new "virtue" respect for nature - which, if pursued, could help prevent environmental degradation, including biodiversity loss. While offsetting might make it economically less viable to destroy biodiversity, it rests on the assumption that there is nothing wrong per se with the manipulation and trading of nature, and may therefore undermine such a virtue. This danger is highlighted by Goodin (1994), who drew a comparison between the monetization of nature and the selling of "indulgences" by Catholic clergy in the Middle Ages, whereby monetary payment was given in remittance for sinful living.

A utilitarian ethic for environmental protection may actually exacerbate environmental harm. In their study of childcare centers in Israel, Gneezy and Rustichini (2000) showed that the introduction of late pick-up fees resulted in more parents arriving late to collect their children: a trend that persisted even when the fee was abolished. Commodification of the "late pick-up service" changed the ethical basis for punctuality from a respect for the teacher to a market based on a willingness to pay for a service. In the same way, offsetting schemes may be less effective at preventing the loss of biodiversity because there can be no "guilt" attached to the act of buying a commodity at will (Gneezy and Rustichini 2000).

\section{Conclusion}

Biodiversity offsetting has flourished recently but represents an ethical approach to protecting nature different from that of traditional conservation legislation. Instead of permitting or restricting actions, offsetting is based on maintaining overall ecological value. Even if one does not object fundamentally to the trading of nature, offsetting policies remain problematic because they do not measure the range of values that people associate with biodiversity. Ironically, offsetting may exacerbate environmental harm because it removes an important ethical roadblock to its destruction. It is critical therefore to consider the ethical implications of this change. Indeed, offsetting raises broader questions about how we should measure impacts to biodiversity, the level of impact we are willing to accept, and what motivates our desire to avoid such impacts. Thus, rather than accepting the inevitable rise of biodiversity offsetting, perhaps it is time to reassess conservation's ethical foundations to ensure that the systems designed to conserve biodiversity are protecting what really matters. 


\section{Acknowledgements}

CDI and SAB thank M Colyvan for insights and helpful comments on an earlier draft of this manuscript. M Hardy assisted with background research on global offset schemes. J Bull, A Gordon, D Keith, and M Maron helped in collating data for Figure 1. The graphic in Figure 1 was designed by TBJ Creative. SAB is supported by an Australian Research Council (ARC) Future Fellowship. This research was conducted with funding from the ARC Centre of Excellence for Environmental Decisions and the Australian Government's National Environmental Science Programme.

\section{References}

Bayon R and Jenkins M. 2010. The business of biodiversity. Nature 466: 184-85.

BBOP (Business and Biodiversity Offsets Programme). 2012. Standard on biodiversity offsets. Washington, DC: BBOP. http://bbop.forest-trends.org/guidelines/Standard.pdf. Viewed 28 Sep 2015.

Bekessy SA, Wintle BA, Lindenmayer DB, et al. 2010. The biodiversity bank cannot be a lending bank. Conserv Lett 3: 151-58.

Bull JW, Suttle KB, Gordon A, et al. 2013. Biodiversity offsets in theory and practice. Oryx 47: 369-80.

Daniel TC, Muhar A, Arnberger A, et al. 2012. Contributions of cultural services to the ecosystem services agenda. P Natl Acad Sci USA 109: 8812-19.

European Commission. 2015. Results of the no net loss public consultation. http://ec.europa.eu/environment/nature/bio diversity/nnl/results_en.htm. Viewed 15 May 2015.

Gibbons P and Lindenmayer DB. 2007. Offsets for land clearing: no net loss or the tail wagging the dog? Ecol Manag Restor 8 : 26-31.

Gladstone Ports Corporation. 2012. Western Basin Dredging and Disposal Project: Biodiversity Offset Strategy. Gladstone, Australia: Gladstone Ports Corporation Limited. www.western basinportdevelopment.com.au/media/pdf/Biodiversity\%200ffset \%20Strategy\%20Version\%206\%20for\%20web.pdf. Viewed 28 Sep 2015.

Gneezy U and Rustichini A. 2000. A fine is a price. J Legal Stud 29: $1-17$.

Goodin R. 1994. Selling environmental indulgences. Kyklos 47: 573-96.

Gordon A, Bull JW, Wilcox C, and Maron M. 2015. Perverse incentives risk undermining biodiversity offset policies. J Appl Ecol 52: 532-37.

Hursthouse R. 2007. Environmental virtue ethics. In: Walker RL and Ivanhoe PJ (Eds). Working virtue: virtue ethics and contemporary moral problems. New York, NY: Oxford University Press.

Jax K, Barton DN, Chan KMA, et al. 2013. Ecosystem services and ethics. Ecol Econ 93: 260-68.
Justus J, Colyvan M, Regan H, and Maguire L. 2009. Buying into conservation: intrinsic versus instrumental value. Trends Ecol Evol 24: 187-91.

Kenter JO, O'Brien L, Hockley N, et al. 2015. What are shared and social values of ecosystems? Ecol Econ 111: 86-99.

Low SM and Altman I. 1992. Place attachment. New York, NY: Plenum Press.

Maron M, Hobbs RJ, Moilanen A, et al. 2012. Faustian bargains? Restoration realities in the context of biodiversity offset policies. Biol Conserv 155: 141-48.

McCauley DJ. 2006. Selling out on nature. Nature 443: 27-28.

Miller TR, Minteer BA, and Malan LC. 2011. The new conservation debate: the view from practical ethics. Biol Conserv 144: 948-57.

Parkes D, Newell G, and Cheal D. 2003. Assessing the quality of native vegetation: the "habitat hectares" approach. Ecol Manag Restor 4: 29-38.

Purvis A and Hector A. 2000. Getting the measure of biodiversity. Nature 405: 212-19.

Rolston III H. 1988. Environmental ethics: duties to and values in the natural world. Philadelphia, PA: Temple University Press.

Ruhl JB. 1999. How to kill endangered species, legally: the nuts and bolts of Endangered Species Act "HCP" Permits for real estate development. Environ Lawyer 5: 345-406.

Sagoff M. 2008. At the Shrine of Our Lady of Fatima or why political questions are not all economic. In: Sagoff M. The economy of the Earth: philosophy, law, and the environment (2nd edn). Cambridge, UK: Cambridge University Press.

Sagoff M. 2013. What does environmental protection protect? Ethics Policy Environ 16: 239-57.

Sarkar S. 2012. Environmental philosophy: from theory to practice. Malden, MA: Wiley-Blackwell.

Shafer-Landau R (Ed). 2013. Ethical theory: an anthology (2nd edn). Malden, MA: Wiley-Blackwell.

Spash CL. Bulldozing biodiversity: the economics of offsets and trading-in Nature. Biol Conserv; doi:10.1016/j.biocon. 2015.07.037. In press.

UNEP (United Nations Environment Programme). 2005. Concepts of ecosystem value and valuation approaches. In: Millennium Ecosystem Assessment. Ecosystems and human well-being: a framework for assessment. Washington, DC: Island Press. www.unep.org/maweb/documents/document. 304.aspx.pdf. Viewed 28 Sep 2015.

Victorian Government. 2002. Native vegetation management: a framework for action. www.spiffa.org/uploads/2/6/7/5/2675656/ nativevegetationmanagement-aframeworkforaction.pdf. Viewed 28 Sep 2015.

Vidal J. 2014. Conservationists split over 'biodiversity offsetting' plans. The Guardian. 4 Jun 2014. www.theguardian.com/ environment/2014/jun/03/conservationists-split-over-biodiver sity-offsetting-plans. Viewed 28 Sep 2015.

Vucetich JA, Bruskotter JT, and Nelson MP. 2015. Evaluating whether nature's intrinsic value is an axiom of or anathema to conservation. Conserv Biol 29: 321-32.

Walker S, Brower AL, Stephens RTT, and Lee WG. 2009. Why bartering biodiversity fails. Conserv Lett 2: 149-57. 


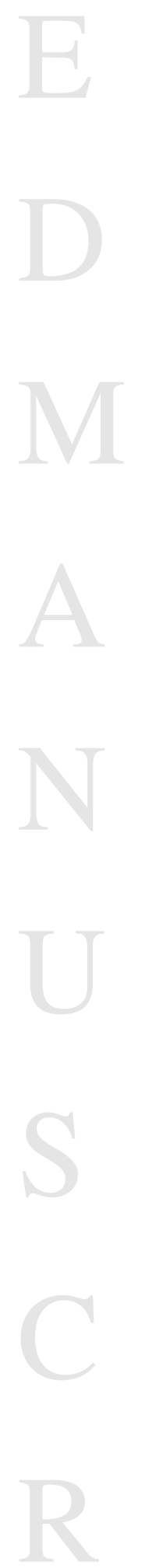


I P 